Article

\title{
Mapping Very-High-Resolution Evapotranspiration from Unmanned Aerial Vehicle (UAV) Imagery
}

\author{
Suyoung Park ${ }^{1, *}$, Dongryeol Ryu ${ }^{2} \mathbb{D}$, Sigfredo Fuentes ${ }^{3} \mathbb{D}$, Hoam Chung ${ }^{4}\left(\mathbb{D}\right.$, Mark $^{\prime}$ Connell $^{5,6}$ \\ and Junchul Kim ${ }^{7}$
}

check for

updates

Citation: Park, S.; Ryu, D.; Fuentes, S.; Chung, H.; O'Connell, M.; Kim, J. Mapping Very-High-Resolution

Evapotranspiration from Unmanned Aerial Vehicle (UAV) Imagery. ISPRS Int. J. Geo-Inf. 2021, 10, 211. https:// doi.org/10.3390/ijgi10040211

Academic Editors:

Filiberto Chiabrando and

Wolfgang Kainz

Received: 15 February 2021

Accepted: 22 March 2021

Published: 1 April 2021

Publisher's Note: MDPI stays neutral with regard to jurisdictional claims in published maps and institutional affiliations.

Copyright: (c) 2021 by the authors. Licensee MDPI, Basel, Switzerland. This article is an open access article distributed under the terms and conditions of the Creative Commons Attribution (CC BY) license (https:// creativecommons.org/licenses/by/ $4.0 /)$.
1 Hort-Eye Pty Ltd., Melbourne, VIC 3000, Australia

2 Department of Infrastructure Engineering, The University of Melbourne, Parkville, VIC 3010, Australia; dryu@unimelb.edu.au

3 Digital Agriculture, Food and Wine Group, School of Agriculture and Food, Faculty of Veterinary and Agricultural Sciences, The University of Melbourne, Parkville, VIC 3010, Australia; sigfredo.fuentes@unimelb.edu.au

4 Department of Mechanical and Aerospace Engineering, Monash University, Clayton, VIC 3800, Australia; hoam.chung@monash.edu

5 Department of Jobs, Precincts and Regions, Tatura, VIC 3616, Australia; mark.oconnell@agriculture.vic.gov.au

6 Centre for Agricultural Innovation, The University of Melbourne, Parkville, VIC 3010, Australia

7 Center for Data Science, Seoul Institute of Technology, Seoul 03909, Korea; kjc@sit.re.kr

* Correspondence: park@horteye.com; Tel.: +61-3-8344-7115

\begin{abstract}
There is a growing concern about water scarcity and the associated decline in Australia's agricultural production. Efficient water use as a natural resource requires more precise and adequate monitoring of crop water use and irrigation scheduling. Therefore, accurate estimations of evapotranspiration (ET) at proper spatial-temporal scales are critical to understand the crop water demand and uptake and to enable optimal irrigation scheduling. Remote sensing (RS)-based ET estimation has been adopted as a method for large-scale applications when the detailed spatial representation of ET is required. This research aimed to estimate instantaneous ET using very-high-resolution (VHR) multispectral and thermal imagery $(\mathrm{GSD}<8 \mathrm{~cm}$ ) collected using a single flight of a UAV over a high-density peach orchard with a discontinuous canopy. The energy balance component estimation was based on the high-resolution mapping of evapotranspiration (HRMET) model. A tree-by-tree ET map was produced using the canopy surface temperature and the leaf area index (LAI) resampled at the corresponding scale via a systematic feature segmentation method based on pure canopy extraction. Results showed a strong linear relationship between the estimated ET and the leaf transpiration $(n=42)$ measured using a gas exchange sensor, with a coefficient of determination $\left(\mathrm{R}^{2}\right)$ of 0.89 . Daily ET (5.5 $\left.\mathrm{mm} \mathrm{d}^{-1}\right)$ derived from the instantaneous ET map was comparable with daily crop ET ( $\left.6.4 \mathrm{~mm} \mathrm{~d}^{-1}\right)$ determined by the meteorological approach over the study site. The proposed approach has important implications for mapping tree-by-tree ET over horticultural fields using VHR imagery.
\end{abstract}

Keywords: water use; thermal infrared (TIR) imagery; multispectral (MS) imagery; surface energy balance model (SEBM); high-resolution mapping of evapotranspiration (HRMET)

\section{Introduction}

Water scarcity has long been an important issue in Australia, and has resulted in declined production in irrigated agriculture at a national scale [1]. Efficient water use in agriculture requires improved irrigation management informed by accurate monitoring of crop water requirements. In the case of high-value horticultural crops, e.g., pear, peach, grape, and olive, various studies have investigated the effect of deficit irrigation, including regulated deficit irrigation (RDI) [2,3], to increase fruit quality while maintaining yield [4,5]. The accurate measurement of evapotranspiration (ET) plays a critical role in determining 
optimal irrigation water volume and understanding crop water uptake and loss. In particular, crop ET estimations inform farmers of water consumption and plant available water in the soil, which are key inputs for irrigation management and scheduling.

Various methods have been used to derive field-based ET; weather station based approaches, surface energy balance methods (SEBM), and soil water balance have been investigated and utilized in point measurements for several decades [6]. However, fieldbased ET has a limited utility when expanding the ET values over a large area. In particular, it is not feasible to estimate intra-field ET variations within a crop area [6]. With the consideration of spatial variations within land features (a mixture of vegetated and soil area), remote sensing (RS)-based ET has been adopted as a reliable and feasible method for estimating ET at regional scales [7]. Specifically, remotely sensed ET maps could reproduce spatially varying ET over heterogeneous crop fields at the resolution of the sensor. Satellite images have been used as a major input for RS-based ET estimation for several decades [8]. In general, four categories were proposed as RS-based ET methods [6,9]: (1) the direct empirical method using the direct relationship between ET and the combined RS and meteorological data; (2) the residual method of surface energy balance model; (3) the vegetation index method where a potential or reference ET is calculated from ground measurements and RS data is used to estimate the crop specific factor (crop coefficient) and; (4) deterministic methods based on the soil-vegetation atmospheric transfer (SVAT) model. Among these approaches, the residual method has been widely applied to estimate ET (or latent heat flux), where ET is obtained as a residual in SEBM and other energy balance components (net radiation, sensible heat flux and soil heat flux) are estimated based on the combined empirical and physical relationships [10]. The residual method in SEBM employs remote sensing data as surface temperature input and canopy structural characteristics derived from vegetation indices (e.g., normalized difference vegetation index (NDVI) or leaf area index (LAI)).

Some of the commonly used techniques to estimate ET are the surface energy balance algorithm (SEBAL) [11], the simple surface energy balance index (S-SEBI) [12], the mapping evapotranspiration with internalized calibration (METRIC) [13], and the two-source energy balance model (TSEB) [14,15]. SEBAL, SEBI, and METRIC require the cold and hot reference pixels within the image to estimate ET. The two extreme reference temperatures are allocated to set the limit of the evaporative fraction ( 0 and 1$)$ where the latent heat flux $(\lambda E T)$ is set to 0 on a dry surface and sensible heat energy $(H)$ is set to 0 on a wet surface, respectively [11]. On the other hand, the TSEB does not require the extreme references within the image and partitions the sensible and latent energy fluxes separately from the canopy and soil in one pixel (or unit area). TSEB has been proven to be a reliable method to estimate $\mathrm{E}$ and $\mathrm{T}$ for uniform and row-crop fields.

The RS-based methods were designed to estimate ET over a relatively large area with primary input images from satellites. Satellites can provide the visible, near-infrared (VISNIR), and thermal (TIR) bands with a spatial resolution of $30 \mathrm{~m}-1.0 \mathrm{~km}$, e.g., Landsat 7 with VISNIR $30 \mathrm{~m}$ and TIR $60 \mathrm{~m}$, Landsat 5 with $30 \mathrm{~m}$ and $120 \mathrm{~m}$, and MODIS with $0.5 \mathrm{~km}$ and $1 \mathrm{~km}$, respectively. However, when an ET estimate is required at the resolution of small fields or trees for precision agriculture, the resolution of typical satellite data is too coarse to provide the fine information required for plant water use. In addition, the temporal resolution is rather low to capture a target area in a projected time on demand since a satellite's revisit cycle is usually several days $[8,16,17]$. On the other hand, highresolution TIR and VISNIR imagery acquired by an unmanned aerial vehicle (UAV) can provide surface information at a resolution higher than $10 \mathrm{~cm}$ depending on the flight altitude and camera sensor specifications [18-21]. The high-resolution imagery from a UAV enables capturing tree-level variabilities of crop water use and status, such as ET and water stress symptoms. It also facilitates more precise delineation of canopy pixels from the soil background. In the case of heterogeneous fields, e.g., fruit tree crops, if low-resolution imagery is used, it is difficult to show intra-field characteristics separately from tree rows and inter-rows as the imagery includes many mixed pixels of trees and soil [22]. The 
TSEB has been widely applied to partition the energy fluxes from the tree canopy and soil in the mixture pixels on this subject. As one of the ET methods for high-resolution imagery, Zipper and Loheide Ii [16] introduced a combined model of one-source and two-source schemes using a pixel-based ET estimate, called high-resolution mapping of evapotranspiration (HRMET). HRMET is designed to partition the available energy (net radiation) to the canopy and soil in a pixel and then calculates the sensible and latent heat flux iteratively. HRMET relies on simplified inputs that can be practically obtained from remotely sensed data and basic meteorological data. The other advantage of the model is that it does not require wet and dry reference features to calculate turbulent fluxes in the imagery.

In this study, tree-level energy balance components were estimated based on HRMET using UAV-borne multispectral and thermal data. The study area is a small-size peach orchard showing heterogeneous field characteristics due to tree crops with tree rows and inter-rows. Therefore, typical coarse resolution from satellite imagery has limitations in the intra-field ET characterization. Thus, this study included very-high-resolution imagery to represent the spatial variability of ET more accurately within the field by dealing with heterogeneous land cover, discontinuous canopy cover, and mixed features of vegetation and soil. The main objective is to assess the sub-field-scale variability of ET over a dripirrigated peach orchard.

\section{Materials and Methods}

\subsection{Study Site}

The experiment was carried out on 19 January 2017 at peach and nectarine orchards ( $0.95 \mathrm{ha}, 140 \mathrm{~m} \times 58 \mathrm{~m})$ near Tatura, Victoria, Australia $\left(36^{\circ} 26^{\prime} 08^{\prime \prime} \mathrm{S}, 145^{\circ} 16^{\prime} 13^{\prime \prime} \mathrm{E}, 114 \mathrm{~m}\right.$ AMSL), administrated by the Department of Jobs, Precincts, and Regions (DJPR) (Figure 1). The climate of Tatura is temperate. The annual rainfall is approximately $480 \mathrm{~mm}$, and the average yearly $\mathrm{ET}_{\mathrm{o}}$ (reference crop evapotranspiration) is $1190 \mathrm{~mm}$.

(a)

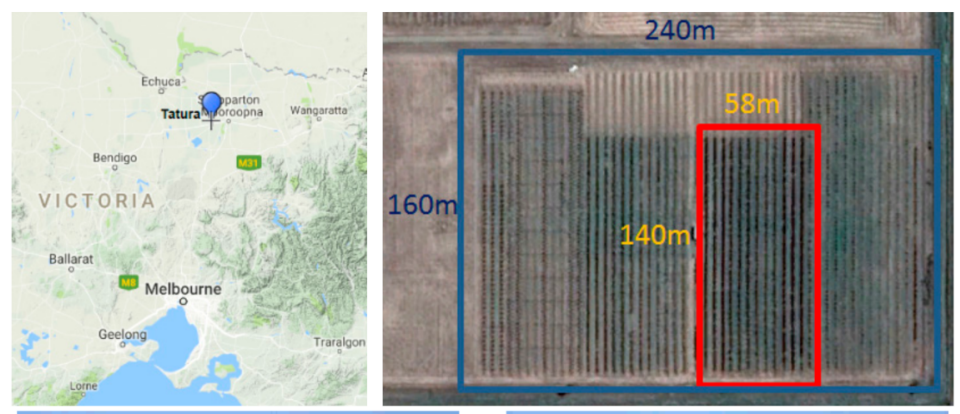

(b)

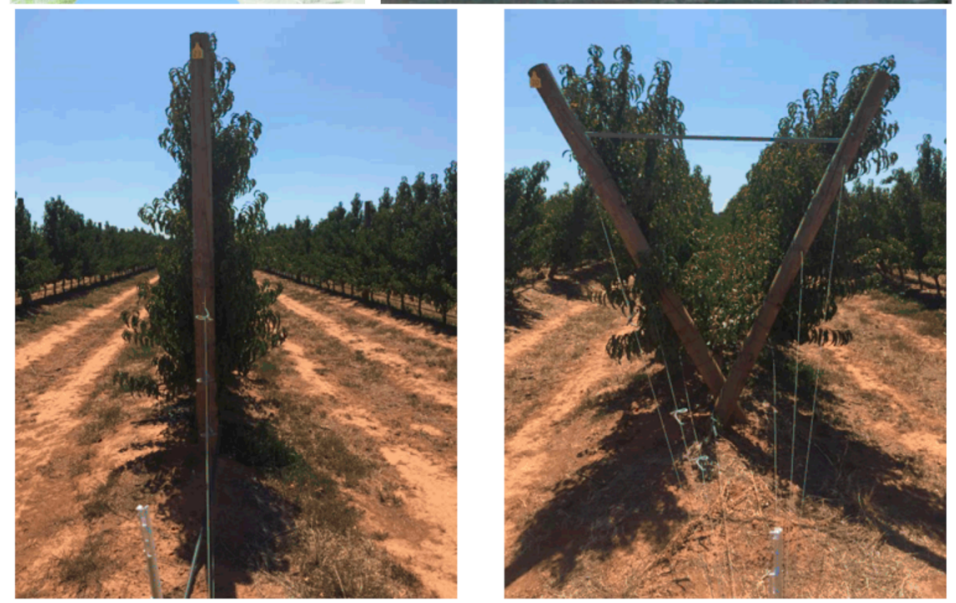

Figure 1. (a) Location of the study site; Stonefruit Experimental Orchard (Tatura, Victoria. Australia). Image source from Google Maps. (b) Canopy structures in vertical leader (left) and Tatura trellis (right). Photos taken midseason (January 2017) at midday (solar noon) looking in a north direction. 
The study site has two tree crops: a peach (Prunus persica (L.) Batsch cv. August Flame); and a nectarine (Prunus persica (L.) Batsch cv. Autumn Bright). The nectarine and peach trees were planted in 2013 , presenting a late fruit maturity phenological stage at full leaf-up at the moment of measurments. Each cultivar is trained to two canopy structures: a vertical leader (VL) with a canopy size of $2.0 \mathrm{~m}$ high $\times 0.8 \mathrm{~m}$ wide, and a Tatura trellis (TT) with a canopy size of $1.9 \mathrm{~m}$ high $\times 1.0 \mathrm{~m}$ wide trellis arms (Figure $1 \mathrm{~b}$ ). TT is in a Y shape with two arm branches since TT's architecture is designed to maximize the leaf surface exposed to capture the sun to enhance productivity $[23,24]$. The trees were planted in a north-south direction in fine, sandy, loamy, Shepparton soil. The tree spacing is $1.0 \mathrm{~m}$ and the inter-row distance is $4.5 \mathrm{~m}$. The orchard was drip-irrigated daily, and the irrigation amount was calculated by a weather-based ETc (crop evapotranspiration) model [25].

\subsection{Data Acquisition}

\subsubsection{Net Radiation and Micrometeorological Data}

A tower was installed to measure both net radiation and micrometeorological data near the center of the study area. A net radiometer with four components (NR01, Hukseflux Thermal Sensors B.V., Delft, The Netherlands) measured net radiation, incoming/outgoing short wave radiation, and longwave radiation $2.6 \mathrm{~m}$ above ground level (AGL) and $0.6 \mathrm{~m}$ above the trees. Temperature and humidity (HMP155, Vaisala Corporation, Helsinki, Finland) sensors were installed above the tree. A wind monitor (Wind Monitor-AQ, R.M. Young Company, Traverse City, MI, USA) was placed at the top of the tower at $4 \mathrm{~m} \mathrm{AGL}$ and measured wind speed and direction.

\subsubsection{Crop Physiology and Solar Radiation Interception Data}

The measurement of crop physiological data was carried out at four adjacent trees in the same three-row where the tower was installed. Leaf temperature was measured in both sunlit and shaded leaves using a handheld infrared thermometer (TN410LCE, ZyTemp, Radiant Innovation Inc., HsinChu, Taiwan). Gas exchange measurements were performed using a photosynthesis system (LI-6400, LI-COR Inc., Lincoln, NE, USA) over three east-sided and three west-sided mature and fully expanded leaves to obtain stomatal conductance $\left(g_{s}, \mathrm{~mol} \mathrm{~m}^{-2} \mathrm{~s}^{-1}\right)$ and transpiration rate $\left(E, \mathrm{mmol} \mathrm{m}^{-2} \mathrm{~s}^{-1}\right)$ per tree was measured ( $n=6_{\text {leaves }} \times 7$ trees $\left.=42_{\text {observations }}\right)$. The measurements were averaged to a single transpiration rate to represent a tree's status. Photosynthetically active radiation (PAR) was measured above and under the canopy for light interception using a ceptometer (Sunfleck, model SF-80, Decagon Devices Inc., Washington, DC, USA). All measurements were carried out near solar noon.

\subsubsection{UAV Field Campaign}

The UAV campaign was conducted on the day of clear sky with moderate wind $\left(0.6 \mathrm{~m} \mathrm{~s}^{-1}\right)$, air temperature $\left(30.6^{\circ} \mathrm{C}\right)$, and relative humidity $(26.7 \%)$. A thermal infrared (TIR) camera (A65, FLIR Systems, Inc., Wilsonville, OR, USA) and multispectral (MS) camera (RedEdge, MicaSense, Seattle, WA, USA) were integrated with a GPS in an onboard CPU for geo-tagging. All the instruments were mounted to a UAV platform (S1000, DJI, Shenzhen, China). The UAV used was an octocopter aircraft, and the maximum capacity of the payload is $11 \mathrm{~kg}$.

All aerial images from TIR and MS sensors were taken by a single flight within the short time window ( $<15 \mathrm{~min}$ ) to capture the homogenous features at midday over the site. TIR images were captured in the spectrum of $7.5-13 \mu \mathrm{m}$, a spatial resolution of $640 \times 512$ pixels, a focal length of $25 \mathrm{~mm}$, and a FOV of $25^{\circ}(\mathrm{H}) \times 20^{\circ}(\mathrm{V})$. MS images were acquired concurrently with TIR sensing. The MS camera consisted of five discrete bands in the blue $(475 \mathrm{~nm})$, green $(560 \mathrm{~nm})$, red $(668 \mathrm{~nm})$, red edge $(717 \mathrm{~nm})$, and near-infrared (NIR) $(840 \mathrm{~nm})$ spectra. Spatial resolution was $1280 \times 960$ pixels with a focal length of $5.5 \mathrm{~mm}$.

Both cameras were mounted to an active gimbal to enable the images to be acquired at nadir view from the UAV. The UAV sensing was conducted at solar noon to capture 
the period of high ET and minimize the shadows cast by the trees. The UAV flew at an altitude of $90 \mathrm{~m}$ AGL to capture images with over $80 \%$ forward and $40 \%$ side overlap by an autonomous flight plan. In total, 204 snapshots of TIR and 199 multi-band images from the MS camera were captured. The footprint of the TIR image was $39 \mathrm{~m} \times 31 \mathrm{~m}$ with a ground sample distance (GSD) of $6 \mathrm{~cm}$. The MS image had a footprint of $108 \mathrm{~m} \times 81 \mathrm{~m}$ and a GSD of $8 \mathrm{~cm}$.

During the UAV sensing, two types of ground targets were deployed at the site: (1) radiometric calibration target for TIR and MS images, and (2) ground control point (GCP) ground artificial feature (GAF) for image processing. The water body and rubber plates were used to calibrate TIR images as cold and hot features, respectively. Tarps $(3 \mathrm{~m} \times 3 \mathrm{~m})$ in three different reflectance values $(6 \%, 12 \%$, and $33 \%)$ were placed for the calibration of MS images (Figure 2). In total, 24 GCPs were distributed over the field and surveyed by a DGPS with $3 \mathrm{~cm}$ positional accuracy. The specific GCP and GAF targets were designed and used for the bundle block adjustment. These targets were made of aluminum sheets considering the spatial resolution and spectral characteristics of both TIR and MS images.
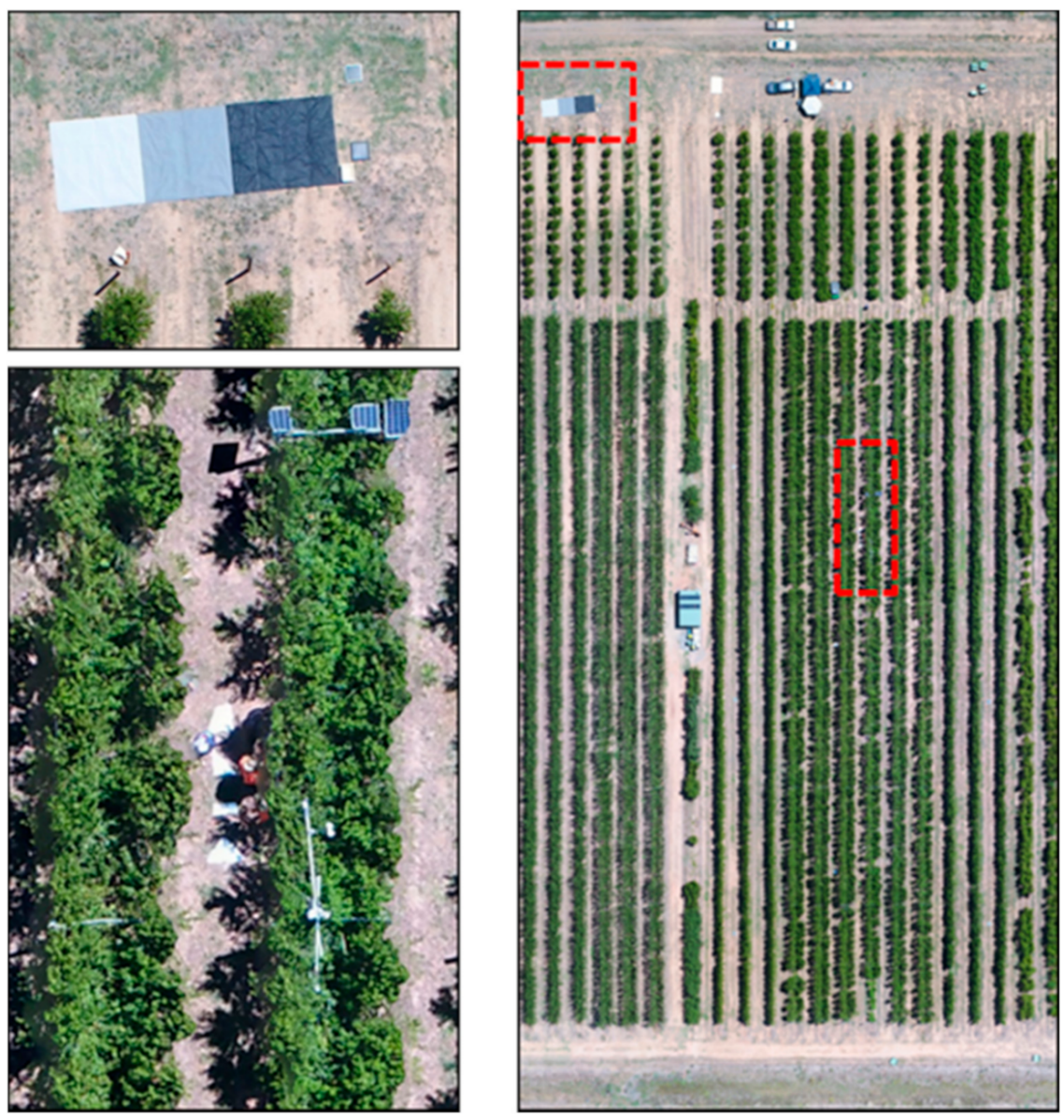

Figure 2. Field description: (top left) radiometric grey targets and temperature targets; (bottom left) the details of sampling trees and meteorological tower; (right) the locations of targets and sample trees are enclosed in red boxes.

\subsection{Remote Sensing Data Processing and ET Modelling}

The data processing and modeling consisted of four steps (Figure 3): (1) RS data processing to produce surface temperature and canopy characteristics variables of ET modeling; (2) tree-by-tree modeling to identify individual plants and allocate the representative spatial variable to each tree; (3) calculation of energy balance components in the ET 
model and mapping instantaneous ET rate and; (4) evaluation of the estimated ET with ground measurements.

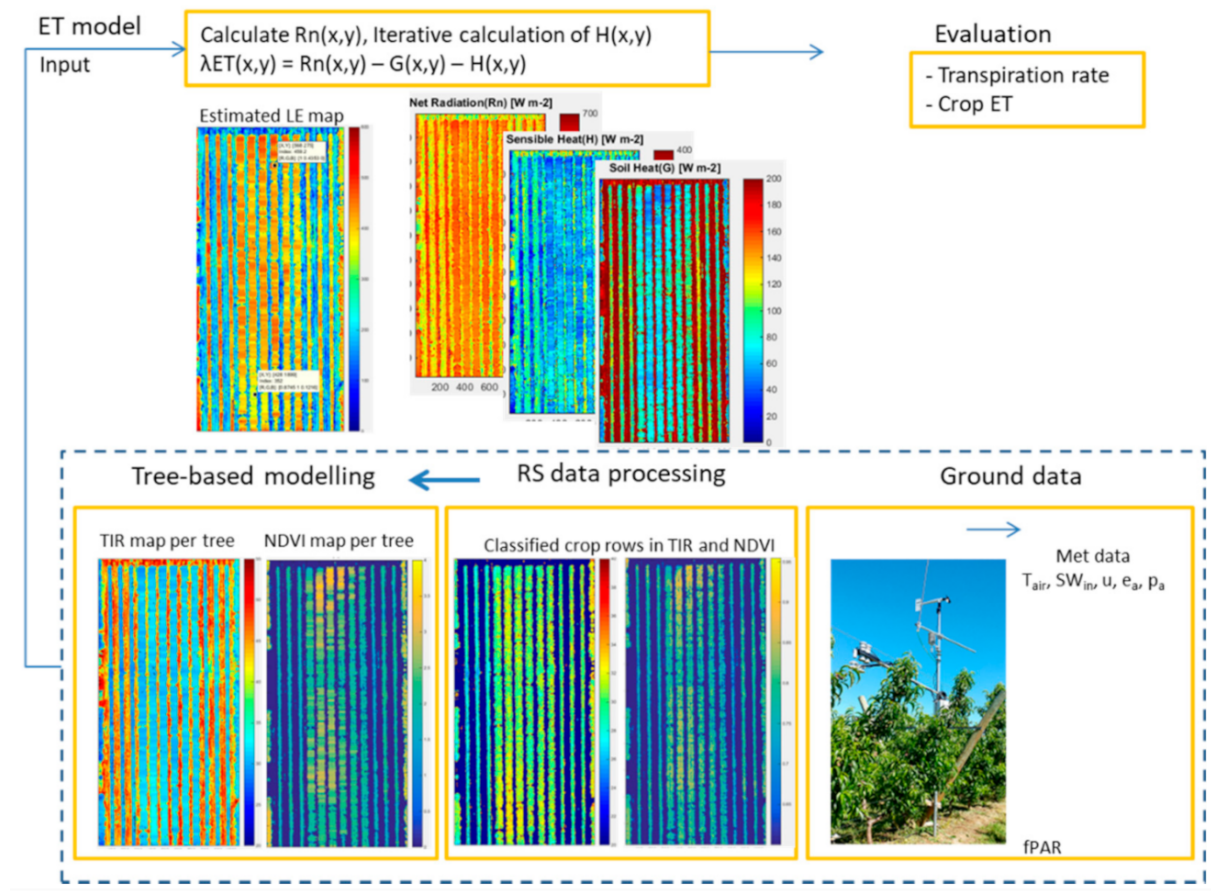

Figure 3. Flow of data processing and modelling.

\subsubsection{Aerial Imagery Processing}

When processing the very high-resolution imagery, a post-calibration process was carried out to produce reliable inputs, which are key factors for the accurate ET estimate. TIR images were recorded in a raw format, consisting of the signal-based values from the surface temperatures. A one-point calibration method [26] was applied to convert the raw digital numbers to temperature values using customized code written in Matlab (Mathworks Inc., Matick, MA, USA). When correlating the raw values to the temperature, calibration targets made of rubber sheets and water bodies were used to refer to the actual temperatures as hot and cold features. The target temperatures were measured with TIR snapshots by a handheld thermal imaging camera (T640, FLIR Systems, Inc., Wilsonville, OR, USA) and a handheld thermometer concurrently at the time of the UAV flight. In the case of MS imagery, radiometric calibration was performed to retrieve the reflectance values in each band. The reflectance measured from three different uniform tarps was correlated to the digital number (DN) values from the MS imagery, and the linear regression relationship was applied to convert all DN values to the reflectance values. All consecutive TIR and MS images were aligned with initial camera positions from onboard GPS in a photogrammetric software (PhotoScan, Agisoft LLC, St. Petersburg, Russia). Then, image processing of point cloud and build mesh/texture/DEM/orthomosaic was performed with the highest accuracy setup. RMSEs of georeferenced MS and TIR were horizontally 0.084 $\mathrm{m}$ and $0.137 \mathrm{~m}$ and vertically $0.229 \mathrm{~m}$ and $0.319 \mathrm{~m}$, respectively.

\subsubsection{Leaf Area Index (LAI) Estimation}

The HRMET model used in this research requires LAI to determine canopy transmittance. LAI can be parameterized as a function of multispectral vegetation indices such as NDVI, simple ratio, and reduced simple ratio [27,28]. For example, NDVI is highly correlated with LAI, and the relationship can be adopted in various forms of a regression model (e.g., general exponential, simple linear, or higher curve model) $[28,29]$. In this research, photosynthetically active radiation (PAR)-based LAI is calculated and correlated to NDVI-based LAI, to obtain a more realistic structure of the canopy per tree as an input 
of the ET model. The exponential regression method [27] was employed to retrieve LAI from remote sensed NDVI.

The reference LAI values were determined using PAR measurements above and under the canopy used to calculate light interception by the canopy in the four sample trees. The measured PAR of each tree consists of transmitted and scattered radiation through the canopy and within the canopy, respectively. A radiative model of transmitting and scattering was introduced by Norman and Jarvis [30] and simplified [31] as follows:

$$
\begin{gathered}
\tau=\exp \left\{A\left(1-0.47 f_{b}\right) L /\left((1-1 / 2 K) f_{b}-1\right)\right\} \\
K=1 / 2 \cos \theta
\end{gathered}
$$

where $\tau$ : canopy transmittance, $A$ : canopy absorption, $f_{b}$ : fraction of direct radiation, $L$ : LAI, $K$ : coefficient of canopy extinction, and $\theta$ : sun zenith angle.

The canopy transmittance $\tau$ is the ratio of the transmitted PAR to the incident PAR, and $f_{b}$ is the fraction of radiation from the solar beam to the total incident radiation, which is also known as beam fraction. $K$ is the canopy extinction coefficient and can be simplified with the solar zenith angle $(\theta)$. The PAR-based LAI in the reference tree was retrieved by inverting the radiative model (Equation (1)). Then, the LAI map over the study site was estimated by the exponential regression model with the NDVI map generated from MS imagery obtained from UAV sensing.

\subsubsection{Tree Segmentation}

The surface temperature and LAI maps described in the previous sections were generated into the co-registered raster imagery within an approximately 1 pixel error with geo-referenced coordinates. The tree-level analysis was conducted to systematically produce individual plant water use, automated by the informative field descriptions (plant spacing, row spacing, etc.). For the tree-by-tree analysis, the feature segmentation technique was used in this research. First of all, the non-canopy background pixels were excluded in both temperature and LAI imagery using a histogram method. A set of threshold values for surface temperature and LAI was determined to separate the canopy and non-canopy distributions in the histogram. Although we used very-high-resolution imagery over the experimental site, image pixels along the boundaries between the canopy and background soil can present biased surface temperature and NDVI due to the mixed soil-canopy features for the edge pixels and possible leakage of heat from adjacent pixels. To improve the canopy temperature estimation accuracy, the edge pixels along the boundary between canopy and background were removed using the edge detection method. The details of the edge detection method used in the research were presented in the previous study [32]. Second, pixels belonging to individual trees were classified and grouped systematically by the informative field descriptions, i.e., the plant spacing and row spacing distances. The grouped pixels were aggregated and averaged as a representative value of each tree using customized code written in Matlab (Mathworks Inc., Matick, MA, USA).

\subsubsection{RSEB Algorithm in ET Modeling}

The high-resolution mapping of evapotranspiration (HRMET) model was implemented to estimate energy balance components, and subsequently ET in this research. HRMET is a pixel-based surface energy balance model that was developed to incorporate high-resolution RS data. The model's most prominent advantage is that it does not depend on wet and dry reference features to calculate turbulent fluxes in the imagery. Most of the model's input variables can be obtained from RS data, and the model does not require a heavy process and is executed with minimized inputs as a feasible tool to adapt an applicable irrigation scheduling. The algorithm of the model follows the residual method of the general surface energy balance model as in Equation (3):

$$
\lambda E T=R_{n}-H-G
$$


where $\lambda E T$ : latent heat flux $\left(\mathrm{W} \mathrm{m}^{-2}\right) ; R_{n}$ : net radiation at the surface $\left(\mathrm{W} \mathrm{m}^{-2}\right) ; H$ : sensible heat flux to the air $\left(\mathrm{W} \mathrm{m}^{-2}\right)$ and; $G$ : soil heat flux $\left(\mathrm{W} \mathrm{m}^{-2}\right)$.

The instantaneous net radiation was calculated to separate canopy and soil components based on the two-source model [14] as follows:

$$
\begin{gathered}
R_{n}=S_{\text {in }}-S_{\text {out }}+L_{\text {in }}-L_{\text {out }} \\
R_{n}=f_{c} R_{n, c}+\left(1-f_{c}\right) R_{n, s} \\
R_{n, c}=\left(1-\alpha_{c}\right) R_{n}+\varepsilon_{c} L_{\text {in }}-L_{\text {out }, c} \\
R_{n, s}=\left(1-\alpha_{s}\right) R_{n}+\varepsilon_{s} L_{\text {in }}-L_{\text {out }, s} \\
L=\varepsilon \sigma T^{4}
\end{gathered}
$$

where $S_{\text {in }}, S_{\text {out }}, L_{\text {in }}, L_{\text {out }}$ is incoming and outgoing shortwave and incoming and outgoing longwave $\left(\mathrm{W} \mathrm{m}^{-2}\right)$, respectively. The fractional cover $f_{c}$ is derived from LAI. The subscripts $c$ and $s$ stand for canopy and soil. $\alpha$ and $\varepsilon$ represent the surface albedo and emissivity. $\sigma$ is the Stefan-Boltzmann constant, and $T$ is the surface temperature in Kelvin.

The incoming and outgoing shortwave radiation was calculated separately for the canopy and soil using the radiation extinction model in Equations (4)-(7) and the StefanBoltzmann law equation (Equation (8)). Then, soil heat flux was approximated to be $35 \%$ of the net radiation reaching the soil, as follows [14]:

$$
G=0.35 R_{n, s}
$$

The sensible heat flux, $H$, was computed as follows:

$$
H=\rho_{a} c_{p}\left(T_{s}-T_{a}\right) /\left(\Gamma_{H a}+\Gamma_{e x}\right)
$$

where $\rho_{a}$ : the molar density of air $\left(\mathrm{mol} \mathrm{m}^{-3}\right), c_{p}$ : the specific heat of air $\left(\mathrm{J} \mathrm{mol}^{-1} \mathrm{C}^{-1}\right), \Gamma_{\mathrm{Ha}}$ : the aerodynamic resistance to heat transport $\left(\mathrm{s} \mathrm{m}^{-1}\right)$, and $\Gamma_{e x}$ : the excess resistance to heat transport $\left(\mathrm{s} \mathrm{m}^{-1}\right)$.

The model employs an iterative convergence method to calculate $H$, since both $H$ and $\Gamma_{\mathrm{H} a}$ are codependent variables. The level of $H$ affects the aerodynamic stability and the aerodynamic resistance to heat transport [11]. The iterative method of $H$ is described in a flow chart in Figure 4. This method does not require the wet and hot extreme pixels due to the turbulent heat fluxes' iterative calculation.

When the convergence criterion is met, which is a less than $0.1 \%$ change between the consecutive iterations, the latent heat flux of each pixel was computed using the updated sensible heat flux in Equation (3).

\subsubsection{Site-Specific Crop ET}

The crop ET $\left(E T_{c}\right)$ value of the study field was calculated by using reference crop ET $\left(E T_{o}\right)$ and the basal crop coefficient $\left(K_{c b}\right)$ adjusted for tree size as follows:

$$
E T_{c}=K_{c} E T_{o}
$$

where $K_{c}$ is the crop coefficient and can be divided into two coefficients: the soil evaporation coefficient $\left(K_{e}\right)$ and the basal crop coefficient $\left(K_{c b}\right)$ refer to the contribution of soil evaporation and crop transpiration in modeling crop ET, respectively [25]. $K_{c b}$ has been considered to improve the estimation of daily crop water use in irrigated row crops. Thereby, $E T_{\mathcal{C}}$ is expressed as follows:

$$
E T_{c}=\left(K_{e}+K_{c b}\right) E T_{o}
$$


Previous research has determined a $K_{c b}$ of peach whereby a site-specific crop coefficient adjusted for tree size $(1.52 \times$ midday light interception) permits the estimation of orchard ET after Goodwin, et al. [33].

As $E T_{c}$ indicates the daily evapotranspiration, the estimated hourly ET from the UAV sensing was upscaled to the daily value using the extrapolation method [34] as follows:

$$
E T_{d}=\left(L E_{i} / R_{n, i}\right) R_{n, d}\left(c f / \lambda_{v} \rho_{w}\right)
$$

where $L E_{i}$ and $R_{n, i}$ are instantaneous latent heat flux and net radiation and obtained from the estimated energy components. $R_{n, d}$ is the mean net radiation daily $(24 \mathrm{~h})$ and measured by the net radiometer, $c f$ is a unit conversion factor of time, and $\lambda_{v}$ and $\rho_{w}$ are the latent heat of vaporization and water density, respectively.

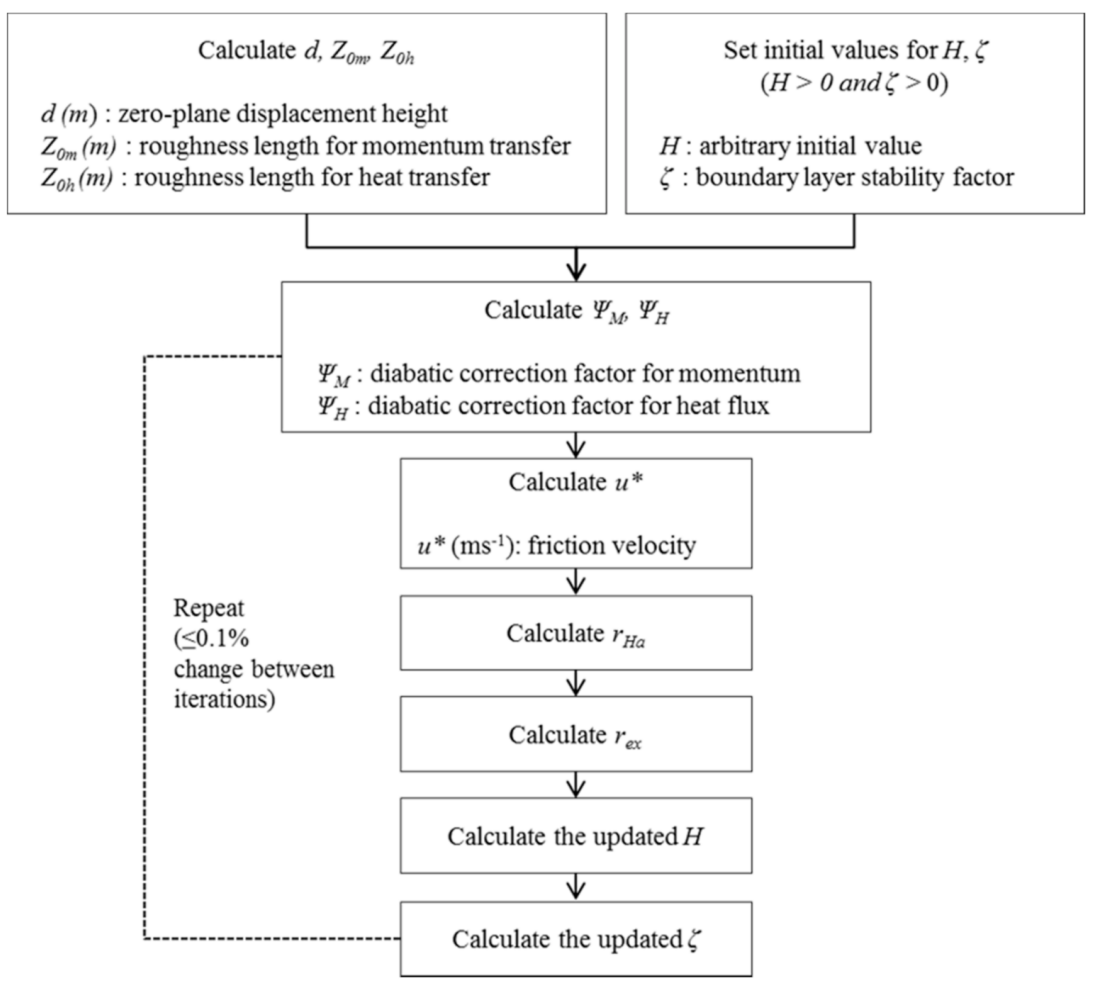

Figure 4. The iterative method of calculating sensible heat flux in the HRMET model.

\section{Results and Discussions}

\subsection{Canopy Temperatures and NDVI}

The study area consisted of two canopy systems for both nectarine and peach trees: vertical leader (VL) and Tatura trellis (TT) as shown in Figure 1b. At the time of UAV flight over the study area, the canopy temperature, captured from TIR sensing, showed spatial variations regarding each canopy system and cultivar. The first three rows were planted with nectarine of VL canopy and had lower temperatures $\left(29.8^{\circ} \mathrm{C}\right)$ compared to the average temperature of the other tree rows $\left(31.7^{\circ} \mathrm{C}\right)$, showing a temperature difference of approximately $2{ }^{\circ} \mathrm{C}$. Figure 5 a shows the intra-field spatial variability of surface temperatures without the soil background in an enhanced contrast colormap. The distributed canopy temperatures over the field were visualized; the temperature of nectarine with VL was cooler than that of the others. The entire study field was under a full-irrigation regime. The coefficient of variation (CV) of canopy temperature was 5.3\% over the orchard. Thus, this result indicated that the canopy temperatures $(T c)$ varied from the different canopy structures and would result in the variability of ET rate. The spatially distributed NDVI was generated using VHR red and NIR imagery from the UAV sensing, shown in Figure $5 b$. The figure presents canopy NDVI, where soil NDVI was classified and excluded using the 
histogram-based method for the tree segmentation process in the next step. Canopy NDVI also showed spatial variability with $4.5 \%$ of $\mathrm{CV}$, which was slightly lower than the $\mathrm{CV}$ of the canopy temperature during the UAV campaign.

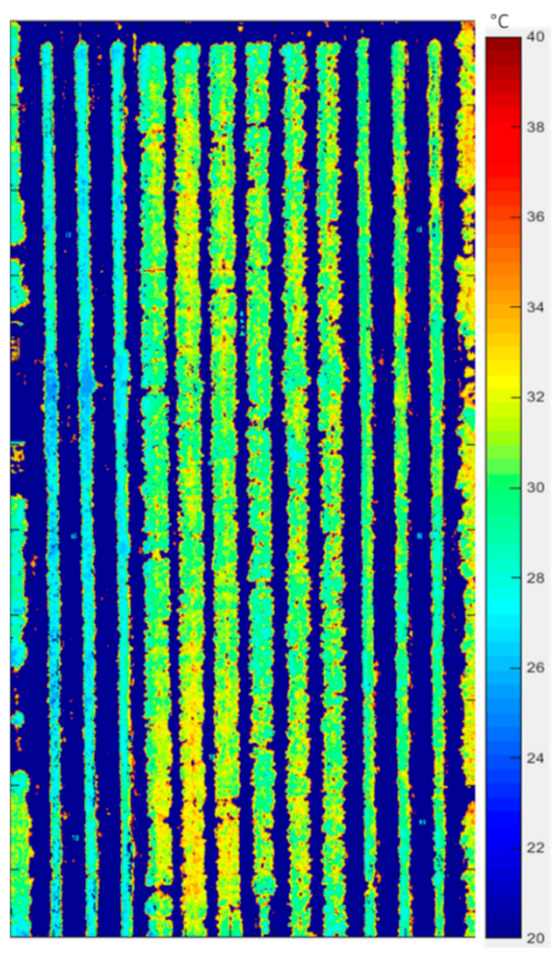

(a)

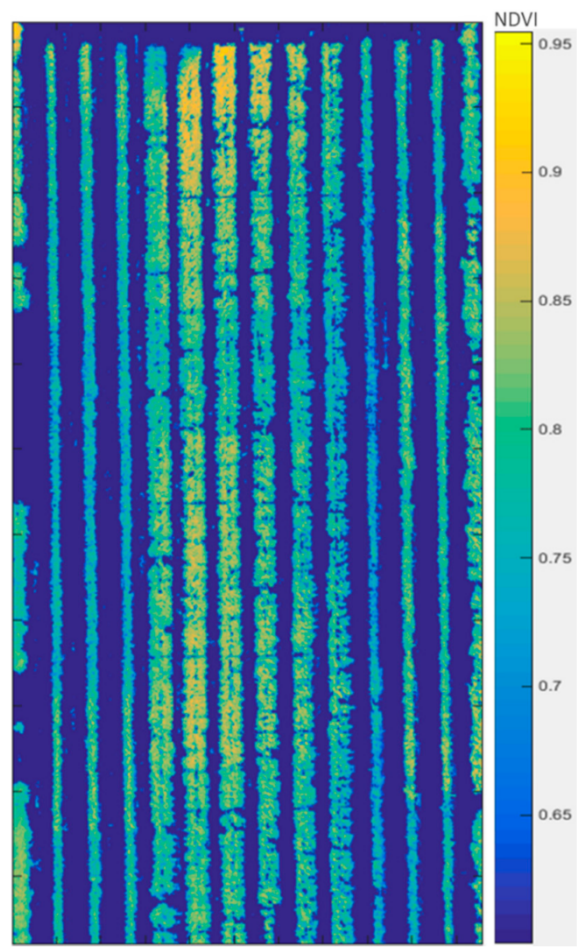

(b)

Figure 5. Tree-row map excluding soil background using tge histogram-based method: (a) surface temperature map $\left({ }^{\circ} \mathrm{C}\right) ;(\mathbf{b})$ NDVI map.

The canopy NDVI in the reference sample trees was compared with the PAR-based LAI and fitted by an exponential relationship [35], resulting in a coefficient of determination $\left(R^{2}\right)$ of 0.9 as shown in Figure 6. We assumed NDVI $=0$ when LAI was reduced to zero. LAI values of the canopies over the whole field were retrieved using the exponential function of NDVI vs. LAI as shown in Figure 5. Since the UAV data acquisition was carried out to capture instantaneous features over the field at the maturity stage, NDVI values from the reference trees varied only within a narrow range of around 0.75 .

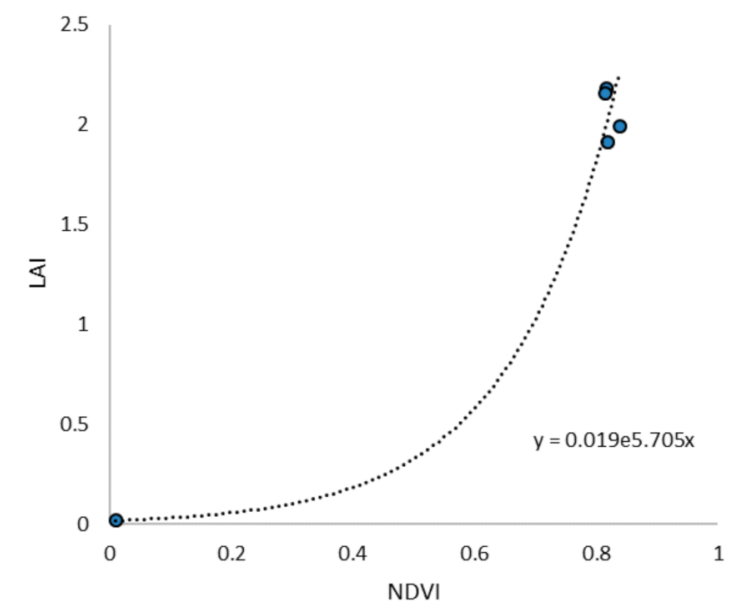

Figure 6. Exponential relationship between PAR-based LAI and NDVI. 
Ideally, a broad distribution of NDVI vs. LAI is required to accurately model the relationship. However, in this research, it was assumed that the retrieved LAI over the field follows the reference PAR-LAI range with an ignorable error, since NDVI values from all trees were in the narrow distribution and were similar to NDVI values from the reference trees [27].

\subsection{Tree-By-Tree Segmentation}

Figure 7 shows the results of the tree-by-tree segmentation both in surface temperature and LAI map. The result of tree-by-tree segmentation represents the possible canopy areas of individual trees. The orchards consisted of 12 rows, and 120 trees were planted in each row.

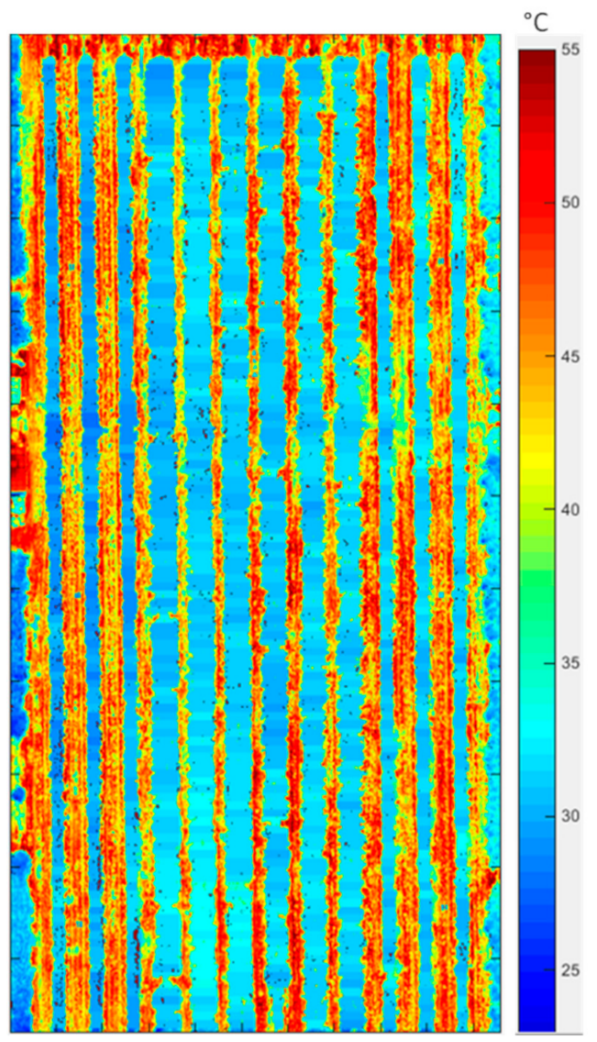

(a)

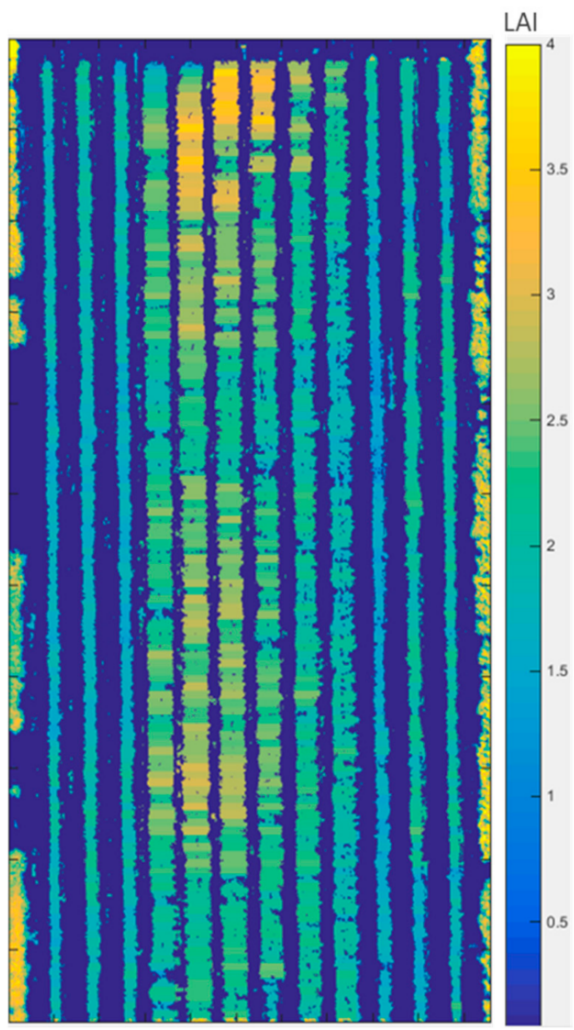

(b)

Figure 7. Tree-by-tree segmentation: (a) surface temperature map $\left({ }^{\circ} \mathrm{C}\right)$ and (b) LAI map.

According to the field descriptions, tree and inter-row spacing are $1.0 \mathrm{~m}$ and $4.5 \mathrm{~m}$, respectively. Using the field descriptions and geo-referenced positioning of each row and tree, each tree section was segmented. Then, the mean value of surface temperature and LAI were assigned to each section as a representative tree value. The results provided better analytic maps to feature the individual plants and interpret the variability between plants, enabling the analysis of tree-by-tree water losses.

\subsection{Energy Balance Components}

The energy balance components, including latent heat flux, were estimated using the HRMET model, and the hourly ET was calculated over the study field, as shown in Figure 8. The original HRMET model has been tested in a uniform surface area with a spatial resolution of 1-2.5 $\mathrm{m}$ of thermal and $30 \mathrm{~m}$ of multispectral inputs under the assumption of uniform meteorological conditions over small-sized fields ( 9 ha and 12 ha). Although this study site presents different site characteristics (e.g., discontinuous canopy cover, tree crops, inter-row soil), HRMET can be applied to examine high-resolution ET since only vegetated pixels were aggregated to individual trees and calculated in the energy 
balance model. This was possible as very-high-resolution $(<8 \mathrm{~cm})$ RS data and a small-sized field ( $<1 \mathrm{ha}$ ) were employed in this study, so precise canopy and soil pixels were classified on account of sufficient spatial resolution data and the removal technique of mixed pixels.

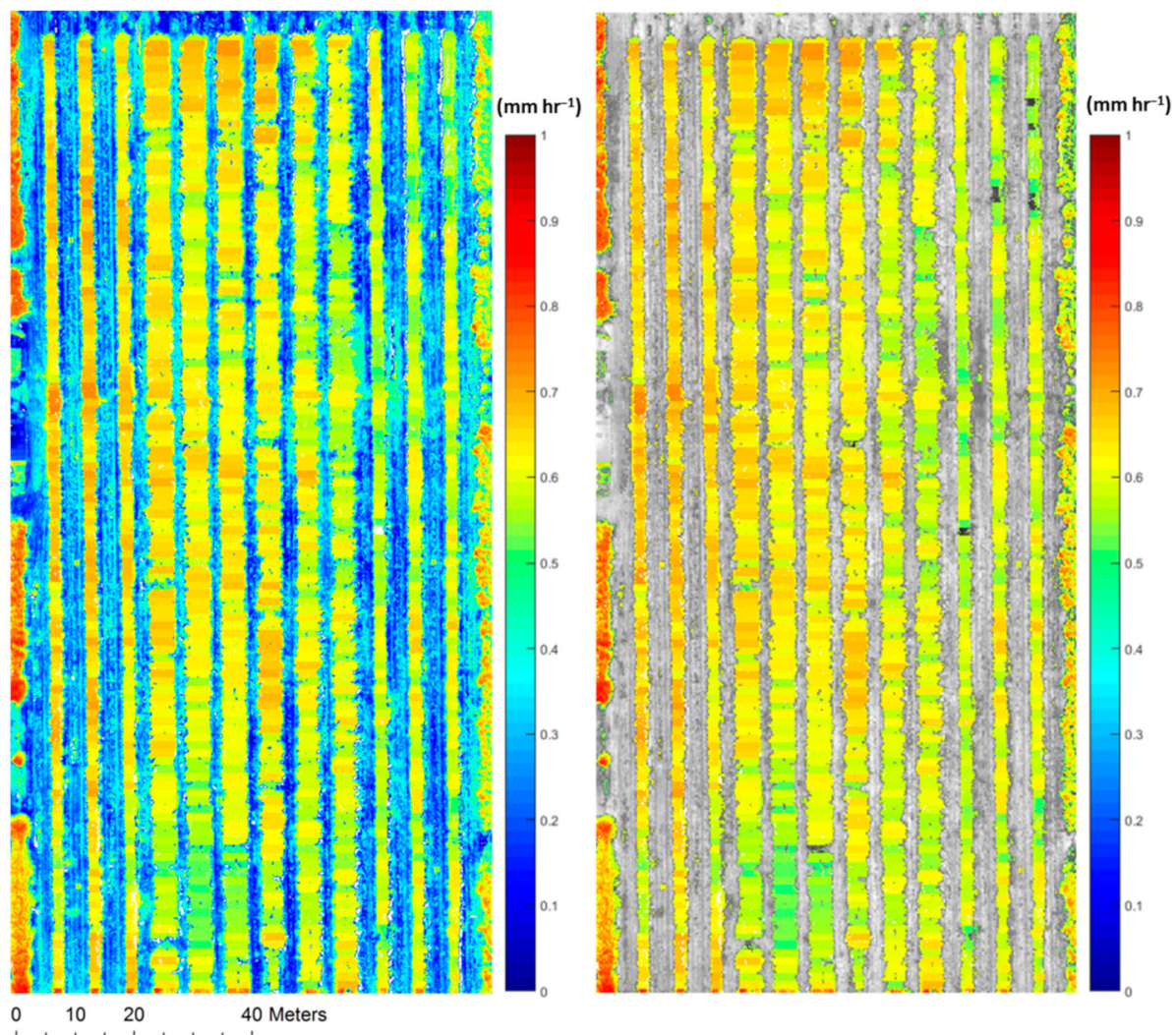

Figure 8. The estimated ET map $\left(\mathrm{mm} \mathrm{h}^{-1}\right)$ : (left) the ET distribution over the orchards; (right) the tree ET with excluded background soil.

The estimated ET in the reference trees was approximately $0.62 \mathrm{~mm} \mathrm{~h}^{-1}$. A relatively higher ET was observed in the first three rows (nectarine with VL) and in the northern part of the tree rows, presenting a rate of $0.76 \mathrm{~mm} \mathrm{~h}^{-1}$ at the most. Since the study field was a small orchard and the UAV data acquisition time was less than $15 \mathrm{~min}$, the meteorological variables such as incoming shortwave radiation, wind speed, and vapor pressure were regarded as consistent across the field. Thus, the different ET rates along the trees were determined, which were mainly derived by the differences of canopy temperature, crop type, and LAI (hence, fractional vegetation cover), as similar patterns were confirmed in the surface temperature map and NDVI (or LAI) map (Figure 7).

The estimated ET was compared with the leaf transpiration rate $\left(\mathrm{mmol} \mathrm{m}^{-2} \mathrm{~s}^{-1}\right)$ measured by the chamber $\left(6 \mathrm{~cm}^{2}\right)$ of gas exchange analyzer (LI-6400) for the reference sample trees, and results with standard deviations are shown in Figure 9.

The estimated ET showed a strong relationship $\left(R^{2}=0.89\right)$ with the average value of leaf transpiration. A coefficient of determination $\left(R^{2}\right)$ would not be a robust indicator to show a significance of correlation with a small dataset. Hence, the magnitude of the relationship (Figure 9) could be over-estimated, as the dataset consists of a small number of measurements. However, the result indicates that the estimated canopy ET was correlated with the ground measurement of leaf transpiration. The leaf-level transpiration measurements may not be the most ideal method as ground truth to compare with treelevel ET in general cases. Since the main factor of the difference in tree-transpiration and tree-ET is related to LAI $[35,36]$ and the experimental orchards were of the same age and maintained rather uniformly in canopy structure and size, it is acceptable to show the correlation of leaf transpiration and tree ET. Although the leaf-level transpiration is not 
comparable with the UAV-borne ET in absolute quantity, the method employed suits the primary focus of demonstrating the utility of UAV-borne TIR imagery to map spatially varying tree-by-tree ET in this work.

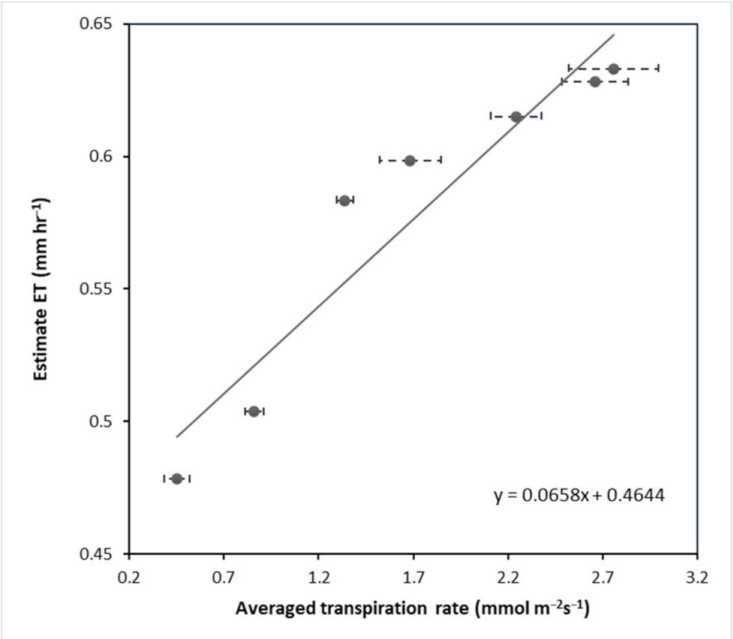

Figure 9. Comparison between the estimated ET and leaf transpiration on the sample trees.

Although the direct measurement of ET such as eddy covariance was not available as the validation data in this research, the crop ET $\left(E T_{c}\right)$ value of the study field was compared with the estimated ET to evaluate the method. Since $E T_{\mathcal{C}}$ is a single value at a field-scale, it has a limitation to present the field-scale comparison with UAV-ET without a sufficient number of repetitions. Under the circumstance of a single-day UAV campaign, the main focus of the comparison, however, was to check that the UAV-born ET is within a reasonable range derived from $E T_{c}$.

As a result, the extrapolated daily (UAV) ET was obtained as $5.50\left(\mathrm{~mm} \mathrm{~d}^{-1}\right)$, whereas the crop ET was calculated as $6.35\left(\mathrm{~mm} \mathrm{~d}^{-1}\right)$. The difference between the two daily ET values was $0.85\left(\mathrm{~mm} \mathrm{~d}^{-1}\right)$. Considering that the extrapolated ET may include estimation errors (e.g., ranging from 0.25 to $1.17 \mathrm{~mm} \mathrm{~d}^{-1}$ ) depending on the extrapolation methods and crop types [34], the estimated daily ET value is within the range of expected ET, showing a comparable value for crop ET. Although it was challenging to evaluate the results thoroughly due to the absence of directly measured ET or multi-seasonal UAV data, the estimated results were compared with leaf transpiration and the daily crop ET to show that the method has the potential to estimate tree-by-tree ET with intra-field variability and to accommodate VHR imagery.

This research method can be supported by further experiments and explored in different sites/cultivars/phenological stages.

\section{Conclusions}

This study examined ET's estimation using very-high-resolution (VHR) multispectral and thermal imagery derived from UAV sensing. The energy balance components were estimated based on the HRMET surface energy balance model. Tree-by-tree analytic maps were produced by the systematic feature segmentation method based on pure canopy extraction and statistical analysis of the distribution of surface temperatures and LAI. A strong linear relationship between the estimated ET and leaf transpiration was obtained in this work. The estimated ET presented a close value to the crop ET over the study site. As remotely sensed NDVI has a limited capability to represent the heterogenous canopy structure of trees, particularly for the vertical profile of canopies, NDVI-based LAI in the proposed method likely poses the same limitation when it is applied to the fields of trees with complex and heterogeneous vertical structures, such as a forest. Thus, the proposed method would be more suited to orchards where planted trees are of similar genetics and 
age and managed by an agronomically uniform method with rather homogenous canopy structure and tree size. The proposed approach can potentially provide a practical method of assessing the intra-field variability of tree-by-tree ET at a sub-field scale for precision irrigation scheduling. Further research on VHR ET estimation comparing RSEB models and crop types is required to develop robust water management information and strategies.

Author Contributions: Conceptualization, Suyoung Park and Dongryeol Ryu; Methodology, Suyoung Park, Dongryeol Ryu Sigfredo Fuentes, Hoam Chung and Mark O'Connell; Software, Suyoung Park and Junchul Kim; Validation, Suyoung Park, Dongryeol Ryu Sigfredo Fuentes, Hoam Chung and Mark O'Connell; Formal Analysis, Suyoung Park; Resources, Suyoung Park, Dongryeol Ryu and Mark O'Connell; Writing-Original Draft Preparation, Suyoung Park; Writing-Review and Editing, Suyoung Park, Dongryeol Ryu Sigfredo Fuentes, Hoam Chung, Mark O'Connell and Junchul Kim. All authors have read and agreed to the published version of the manuscript.

Funding: The stone fruit experimental orchard project (SF12003 and SF17006) was funded by Horticulture Innovation Australia Limited using the Summerfruit levy and funds from the Australian Government with co-investment from DEDJTR.

Data Availability Statement: Not applicable.

Acknowledgments: This research was supported by the University of Melbourne and Department of Economic Development, Jobs, Transport and Resources (DEDJTR), Victoria. In addition, this research was supported by the Seoul Institute of Technology (http:/ /www.sit.re.kr) (2020-AD-002).

Conflicts of Interest: The authors declare no conflict of interest.

\section{References}

1. Qureshi, M.E.; Hanjra, M.A.; Ward, J. Impact of water scarcity in australia on global food security in an era of climate change. Food Policy 2013, 38, 136-145. [CrossRef]

2. Mitchell, P.D.; Chalmers, D.J. The effect of reduced water supply on peach tree growth and yields [irrigation levels]. J. Am. Soc. Hortic. Sci. 1982, 107, 853-856.

3. Goodwin, I.; O Connell, M.G. Drought water management: An australian perspective. In ActaHortic, 1150th ed.; International Society for Horticultural Science (ISHS): Lleida, Spain, 2017; pp. 219-232.

4. Tognetti, R.; d'Andria, R.; Morelli, G.; Alvino, A. The effect of deficit irrigation on seasonal variations of plant water use in Olea europaea L. Plant Soil 2005, 273, 139-155. [CrossRef]

5. Buesa, I.; Perez, D.; Castel, J.; Intrigliolo, D.S.; Castel, J.R. Effect of deficit irrigation on vine performance and grape composition of Vitis vinifera L. Cv. Muscat of alexandria. Aust. J. Grape Wine Res. 2017, 23, 251-259. [CrossRef]

6. Nouri, H.; Beecham, S.; Anderson, S.; Hassanli, A.M.; Kazemi, F. Remote sensing techniques for predicting evapotranspiration from mixed vegetated surfaces. Urban Water J. 2015, 12, 380-393. [CrossRef]

7. Kustas, W.; Anderson, M. Advances in thermal infrared remote sensing for land surface modeling. Agric. For. Meteorol. 2009, 149, 2071-2081. [CrossRef]

8. Xia, T.; Kustas, W.; Anderson, M.; Alfieri, J.; Gao, F.; McKee, L.; Prueger, J.; Geli, H.; Neale, C.; Sanchez, L.; et al. Mapping evapotranspiration with high-resolution aircraft imagery over vineyards using one- and two-source modeling schemes. Hydrol. Earth Syst. Sci. 2016, 20, 1523-1545. [CrossRef]

9. Courault, D.; Seguin, B.; Olioso, A. Review on estimation of evapotranspiration from remote sensing data: From empirical to numerical modeling approaches. Irrig. Drain. Syst. 2005, 19, 223-249. [CrossRef]

10. Kalma, J.D.; McVicar, T.R.; McCabe, M.F. Estimating land surface evaporation: A review of methods using remotely sensed surface temperature data. Surv. Geophys. 2008, 29, 421-469. [CrossRef]

11. Bastiaanssen, W.G.M.; Menenti, M.; Feddes, R.A.; Holtslag, A.A.M. A remote sensing surface energy balance algorithm for land (sebal). 1. Formulation. J. Hydrol. 1998, 212-213, 198-212. [CrossRef]

12. Roerink, G.J.; Su, Z.; Menenti, M. S-sebi: A simple remote sensing algorithm to estimate the surface energy balance. Phys. Chem. Earth Part B Hydrol. Ocean. Atmos. 2000, 25, 147-157. [CrossRef]

13. Allen, R.G.; Tasumi, M.; Trezza, R. Satellite-based energy balance for mapping evapotranspiration with internalized calibration (metric)-model. J. Irrig. Drain. Eng. 2007, 133, 380-394. [CrossRef]

14. Norman, J.M.; Becker, F. Terminology in thermal infrared remote sensing of natural surfaces. Agric. For. Meteorol. 1995, 77, 153-166. [CrossRef]

15. Kustas, W.P.; Norman, J.M. Evaluation of soil and vegetation heat flux predictions using a simple two-source model with radiometric temperatures for partial canopy cover. Agric. For. Meteorol. 1999, 94, 13-29. [CrossRef]

16. Zipper, S.C.; Loheide Ii, S.P. Using evapotranspiration to assess drought sensitivity on a subfield scale with hrmet, a high resolution surface energy balance model. Agric. For. Meteorol. 2014, 197, 91-102. [CrossRef] 
17. Ortega-Farías, S.; Ortega-Salazar, S.; Poblete, T.; Kilic, A.; Allen, R.; Poblete-Echeverría, C.; Ahumada-Orellana, L.; Zuñiga, M.; Sepúlveda, D. Estimation of energy balance components over a drip-irrigated olive orchard using thermal and multispectral cameras placed on a helicopter-based unmanned aerial vehicle (uav). Remote Sens. 2016, 8, 638. [CrossRef]

18. Berni, J.A.J.; Zarco-Tejada, P.J.; Sepulcre-Cantó, G.; Fereres, E.; Villalobos, F. Mapping canopy conductance and cwsi in olive orchards using high resolution thermal remote sensing imagery. Remote Sens. Environ. 2009, 113, 2380-2388. [CrossRef]

19. Zarco-Tejada, P.J.; González-Dugo, V.; Berni, J.A.J. Fluorescence, temperature and narrow-band indices acquired from a uav platform for water stress detection using a micro-hyperspectral imager and a thermal camera. Remote Sens. Environ. 2012, 117, 322-337. [CrossRef]

20. Roy, S.; Ophori, D. Estimation of crop water stress index in almond orchards using thermal aerial imagery. J. Spat. Hydrol. 2014, $12,29$.

21. Rud, R.; Cohen, Y.; Alchanatis, V.; Levi, A.; Brikman, R.; Shenderey, C.; Heuer, B.; Markovitch, T.; Dar, Z.; Rosen, C.; et al. Crop water stress index derived from multi-year ground and aerial thermal images as an indicator of potato water status. Precis. Agric. 2014, 15, 273-289. [CrossRef]

22. Matese, A.; Toscano, P.; Gennaro, S.F.D.; Genesio, L.; Vaccari, F.P.; Primicerio, J.; Belli, C.; Zaldei, A.; Bianconi, R.; Gioli, B. Intercomparison of uav, aircraft and satellite remote sensing platforms for precision viticulture. Remote Sens. 2015, 7, $2971-2990$. [CrossRef]

23. Chalmers, D.J.; Van den Ende, B. Tatura Trellis Peaches: Productivity over Fifteen Year; International Society for Horticultural Science (ISHS): Clemson, SC, USA, 1989; pp. 303-306.

24. Elkins, R.B.; DeJong, T.M. Effect of Training System and Rootstock on Growth and Productivity of Golden Russet ${ }^{\circ B o s c}$ Pear Trees; International Society for Horticultural Science (ISHS): Leuven, Belgium; Ferrar-Bologna, Italy, 2002; pp. 603-607.

25. Allen, R.G.; Pereira, L.S.; Raes, D.; Smith, M. Crop Evapotranspiration: Guidelines for Computing Crop Water Requirements; Food and Agriculture Organization of the United Nations: Rome, Italy, 1998; p. 300.

26. FLIRSystems. User's Manual Flir ax5 Series; T559770; FLIR Systems: Wilsonville, OR, USA, 2013.

27. Fan, L.; Gao, Y.; Brück, H.; Bernhofer, C. Investigating the relationship between ndvi and lai in semi-arid grassland in inner mongolia using in-situ measurements. Theor. Appl. Climatol. 2009, 95, 151-156. [CrossRef]

28. Stenberg, P.; Rautiainen, M.; Manninen, T.; Voipio, P.; Smolander, H. Reduced simple ratio better than ndvi for estimating lai in finnish pine and spruce stands. Silva Fenn. 2004, 38, 3-14. [CrossRef]

29. Steltzer, H.; Welker, J.M. Modeling the effect of photosynthetic vegetation properties on the ndvi-lai relationship. Ecology 2006, 87, 2765-2772. [CrossRef]

30. Norman, J.M.; Jarvis, P.G. Photosynthesis in sitka spruce (Picea sitchensis (bong.) carr.). V. Radiation penetration theory and a test case. J. Appl. Ecol. 1975, 12, 839-878. [CrossRef]

31. DecagonDevicesInc. Decagon Accupar Ceptometer Operating Manual; Decagon Devices Inc.: Pullman, WA, USA, 2001.

32. Park, S.; Ryu, D.; Fuentes, S.; Chung, H.; Hernández-Montes, E.; O'Connell, M. Adaptive Estimation of Crop Water Stress in Nectarine and Peach Orchards Using High-Resolution Imagery from an Unmanned Aerial Vehicle (UAV). Remote Sens. 2017, 9, 828. [CrossRef]

33. Goodwin, I.; Whitfield, D.M.; Connor, D.J. Effects of tree size on water use of peach (Prunus persica L. Batsch). Irrig. Sci. 2006, 24, 59-68. [CrossRef]

34. Chávez, J.L.; Neale, C.M.U.; Prueger, J.H.; Kustas, W.P. Daily evapotranspiration estimates from extrapolating instantaneous airborne remote sensing et values. Irrig. Sci. 2008, 27, 67-81. [CrossRef]

35. Zhang, Y.; Liu, C.; Lei, Y.; Tang, Y.; Yu, Q.; Shen, Y.; Sun, H. An integrated algorithm for estimating regional latent heat flux and daily evapotranspiration. Int. J. Remote Sens. 2006, 27, 129-152. [CrossRef]

36. Hadiwijaya, B.; Pepin, S.; Isabelle, P.-E.; Nadeau, D.F. The dynamics of transpiration to evapotranspiration ratio under wet and dry canopy conditions in a humid boreal forest. Forests 2020, 11, 237. [CrossRef] 